\title{
Epidemiology of tuberculosis in children in Kampala district, Uganda, 2009-2010; a retrospective cross-sectional study
}

Eric Wobudeya ${ }^{1,2^{*}}$, Deus Lukoye ${ }^{3}$, Irene R. Lubega ${ }^{1,2}$, Frank Mugabe ${ }^{4}$, Moorine Sekadde $^{4}$ and Philippa Musoke ${ }^{2,5}$

\begin{abstract}
Background: The global tuberculosis (TB) estimate in 2011 was 500,000 cases among children under 15 years representing $5.7 \%$ of all cases and 64,000 deaths among HIV negative children representing $6.5 \%$ of the total deaths. In Uganda, the child TB cases reported in 2012 made up less than $3 \%$ of the total cases while recent modelling estimates it at 15-20 \% of adult cases. Mapping of these cases in Kampala district most especially for the children under five years would reflect recent transmission in the various communities in the district. We therefore conducted a retrospective study of reported child TB cases in Kampala district Uganda for 2009-2010 to provide an estimate of child TB incidence and map the cases.
\end{abstract}

Methods: This was a retrospective cross-sectional study on data collected from the health unit TB registers in the five divisions of Kampala district, Uganda. The data was a starting point in preparation for a TB Vaccine study in children. The extracted data spanned a period from 1st January 2009 to 31st December 2010. The projected population of children below 15 years was 637,922 in 2009 and 744,750 in 2010 for Kampala district. We based our projections on the National Bureau of Statistics most recent census report of 2002 before the study duration while assuming a population growth rate of $3.7 \%$ each year. We captured the data into EPI DATA 3.1 and analysed it using STATA version 12.

Results: We accessed 15,499 records and analysed 1167 records that were of children below 15 years old. The child TB cases represented $7.5 \%$ (7.3 in 2009 \& $7.6 \%$ in 2010) of all the registered cases in Kampala district. The females were $47 \%$ and the median age was 4 years (IQR 1, 10). The percent of children less than 5 years old was $54 \%$. The percent of pulmonary TB cases was $89 \%(1041 / 1167)$ with $15 \%$ smear positive. The proportion of extra-pulmonary TB cases was $11 \%(126 / 1167)$. Among those that tested for HIV, $60 \%$ (359/620) had test results available with an HIV co-infection rate of $47 \%$ (168/359). Antiretroviral treatment uptake was $24 \%$ among the co-infected. The incidence of child TB in Kampala was 56 (95 \% Cl 50-62) per 100,000 in 2009 and 44 (95 \% Cl 40-49) per 100,000 in 2010. Most of the TB cases $(60 \%(410 / 685))$ in Kampala live in slum areas.

Conclusion: There was a higher child TB incidence of 56 per 100,000 in 2009 compared with 44 per 100,000 in 2010. The percentage of child TB cases was much higher at $7.5 \%$ of all the reported TB cases than the WHO reported national average. For the review period, the TB cases clustered in particular slums in Kampala district.

\footnotetext{
* Correspondence: ewobudeya@gmail.com

'Directorate of Paediatrics \& Child health, Mulago National Referral Hospital,

P. O. Box 7051, Kampala, Uganda

${ }^{2}$ MU-JHU Research Collaboration, P. O. Box 23491, Kampala, Uganda

Full list of author information is available at the end of the article
}

(c) 2015 Wobudeya et al. Open Access This article is distributed under the terms of the Creative Commons Attribution 4.0 International License (http://creativecommons.org/licenses/by/4.0/), which permits unrestricted use, distribution, and reproduction in any medium, provided you give appropriate credit to the original author(s) and the source, provide a link to the Creative Commons license, and indicate if changes were made. The Creative Commons Public Domain Dedication waiver (http://creativecommons.org/publicdomain/zero/1.0/) applies to the data made available in this article, unless otherwise stated. 


\section{Background}

In 2011, the global TB estimate was 8.7 million incident cases with the African region accounting for $26 \%$ and 1.4 million deaths including 430, 000 deaths among HIV-positive people [1]. The 2011 estimates represented for the first time the expanded inclusion of data in children beyond smear positive cases. In the same report, there were an estimated 500, 000 cases among children under 15 years old representing $5.7 \%$ of all cases and 64, 000 deaths in children $6.5 \%$ of the global deaths [1]. Until the global tuberculosis report of 2012, reported PTB cases were the smear positives and therefore included few children. Children mainly have paucibacillary (low TB germ load) disease so are usually smear negative. Consequent to the paucibacillary nature of TB in children, the true burden of TB disease in children remains uncertain.

A recent mathematical modelling estimated about 650,000 incident TB cases in children under 15 years old in 2010 and about 7.5 Million TB infections [2]. There were however no global estimates for the 2010 incident TB cases in children for comparison. The model further estimated that $4-20 \%$ of global TB cases occurs in children while for Uganda it estimated that 15-20\% the cases should be among children [2]. The challenge of childhood TB diagnosis coupled with misdiagnosis of extra-pulmonary TB contributes to uncertain estimates.

Although TB and HIV epidemics link, the drop of $50 \%$ in HIV infection between 2001 and 2012 [3] does not compare with the $2 \%$ decline in TB incidence between 1990 and 2012 [4]. Most of the TB decline is in South-East Asia specifically China. Uganda has registered a remarkable decline in the prevalence of TB and is on track to meet the Millennium Development Goal (MDG) target [5]. We do not know if the decline is in all communities or a few selected population areas. There is a high risk of TB disease in exposed children most especially those with HIV infection and severe malnutrition $[6,7]$. The interplay between $\mathrm{TB}$, poverty and overcrowding [8] leads to varying trends in different populations.

In Uganda, the TB cases reported in children in 2012 made up less than $3 \%$ of the total reported TB cases [4]. There is a high likelihood of TB under-reporting in children because most are diagnosed on clinical basis as opposed to bacteriologically confirmed. We also expect the numbers in children to be a reflection of adult numbers since their TB disease is commonly from adults. Tuberculosis in under fives represents recent transmission reflected in mapping of cases in communities [9]. Until 2012, the World TB reports data for Uganda did not provide information on all forms of childhood TB reported. Age broken down data and TB cases location information is important for targeted interventions and may guide the choice of $\mathrm{TB}$ research populations.
The specific objective this cross-sectional retrospective study was to provide an estimate of incidence and distribution of childhood TB in Kampala district, Uganda.

\section{Methods}

\section{Study design}

This was retrospective study on data collected from health unit $\mathrm{TB}$ registers as starting data in preparation for a $\mathrm{TB}$ vaccine study in children.

\section{Setting}

We collected data from the five administrative divisions of Kampala district. Kampala city, the capital city of Uganda is located in Kampala district. It has an estimated population of 1.5 million by night and much higher by day due to large numbers that come to work. Kampala district is surrounded by Wakiso district from where many people travel to work in the capital city. The district has 62 informal settlements referred to as slums. The district had a projected population of children below 15 years of 637,922 in 2009 and 744,750 in 2010. The projection was from the National Bureau of Statistics 2002 population census report (which was the most recent before the study period) assuming a constant annual population growth rate of $3.7 \%$ [10]. During the study period, TB surveillance in most of the health unit was mainly passive. In the passive surveillance patients present to the health unit for TB related symptoms. In active TB surveillance patients presenting to the health unit for any reason are screened for TB. Active TB surveillance or screening was limited to HIV clinics. There are $52 \mathrm{~TB}$ diagnostic and treatment units (DTU) in the Kampala district. Each of the DTUs registers $\mathrm{TB}$ cases in the Unit TB registers.

\section{Data source}

We reviewed all extracted routine NTLP data from 1st January 2009 to 31st December 2010 from the health unit TB registers in Kampala district, Uganda. Following the clinician's diagnosis, unit TB focal person or TB staff record patient data in paper based unit TB registers. We used the national guideline definitions as adapted from WHO TB guidance of 2006 for case classification during the review period [11]. A case of TB was one with bacteriological confirmation (sputum smear positive or culture) or where a clinician decided to treat for TB. Each TB case is reported as pulmonary TB (smear positive or smear negative or smear not done) or extra pulmonary TB. Since not all children had sputum collected, we included PTB smear not done as a category for intervention purposes. All the TB cases are offered an opportunity to test for HIV as part of the routine tests. 


\section{Data management and statistical analysis}

We captured the data in EPI DATA 3.1 and analysed using the STATA version 12. We described continuous data using medians with inter-quartile ranges while categorical data as proportions. We present the data in tables and graphs. We only included cases of children residing in Kampala district at registration time to calculate incidence rates for Kampala district.

\section{Ethical considerations}

The study received ethical approval from Mulago Hospital Research and Ethics committee and consent obtained from the NTLP of the Ministry of Health. We only extracted non-identifying data.

\section{Results}

We accessed 15,499 patient TB records and extracted 1167 records of children less than 15 years for analysis.

\section{Descriptive data}

Children accounted for $7.5 \%$ (7.3 in 2009 \& $7.6 \%$ in 2010) of all the reported TB cases in Kampala. The median age was 4 years (IQR 1,10$)$ and the majority $(54 \%)$ were under 5 years old with $47 \%$ (548/1167) being females. See Table 1 for other demographic characteristics. Most of the children were $0-4$ years making up $54 \%$, those 5-9 years made up $21 \%$ and the $10-14$ years were $25 \%$. The TB cases residing in Kampala were $59 \%$ while those residing outside Kampala district were $41 \%$ (Wakiso -20\%, elsewhere- $21 \%$ ).

Table 1 Demographic characteristics of the children with TB notified in Kampala district, Uganda 2009-2010 ( $N=1167)$

\begin{tabular}{llll}
\hline Characteristic & & Frequency of TB cases & Percentage \\
\hline Age group in years & $0-4$ & 629 & $54 \%$ \\
& $5-9$ & 246 & $21 \%$ \\
District & $10-14$ & 292 & $25 \%$ \\
& Kampala & 685 & $59 \%$ \\
& Wakiso & 238 & $20 \%$ \\
Division & Others & 244 & $21 \%$ \\
& Kawempe & 172 & $25 \%$ \\
& Makindye & 139 & $20 \%$ \\
Sex & Central & 38 & $5.6 \%$ \\
& Nakawa & 120 & $17 \%$ \\
TB type & Rubaga & 216 & $31 \%$ \\
Sputum collected & Female & 548 & $47 \%$ \\
& Male & 619 & $53 \%$ \\
& PTB & 1041 & $89 \%$ \\
& EPTB & 126 & $11 \%$ \\
& No & 711 & $39 \%$ \\
\hline
\end{tabular}

Seventy five percent (874/1167) had HIV test counselling, $71 \%(620 / 874)$ were tested and results were available for $60 \%$ (359/620). More children under five had unknown HIV status than other age groups (57\% vs $48 \%$ ). Table 2 shows some other characteristics of children with known and unknown HIV status. Of those children with available results, $47 \%$ (168/359) were HIV-positive. Twenty four percent (40/168) of the children with HIV co-infection were on antiretroviral therapy (ART) while $84 \%(141 / 168)$ were on cotrimoxazole prophylaxis therapy (CPT).

There were $89 \%(1041 / 1167)$ PTB cases and $10 \%$ $(126 / 1167)$ EPTB cases. Among the children with pulmonary TB (PTB), 30 \% (308/1041) had HIV test results of which $47 \%(144 / 308)$ were positive. Among extrapulmonary TB (EPTB) cases, $40 \%$ (51/126) had HIV test results of which $47 \%(24 / 51)$ were positive. The HIV positivity rate by age groups was; $47 \%$ in $0-4,59 \%$ in $5-9$ and $26 \%$ in $10-14$ years. The differences were statistically significant (see Table 3).

Of the PTB cases, $15 \%(160 / 1041)$ were sputum acidfast bacilli smear positive, $16 \%(170 / 1041)$ were sputum acid-fast bacilli smear negative and $68 \%$ (711/1041) had no smear done (no sputum collected). Among those with smear not done, most (68\%) were below 5 years old. There was a higher number of PTB cases with smear not done in 2010 (69\%) compared with $53 \%$ in 2009 as shown in Fig. 1. The smear positive and smear

Table 2 Characteristics of children with known and unknown HIV status notified as TB in Kampala district, Uganda 2009-2010 $(N=1167)$

\begin{tabular}{|c|c|c|c|c|}
\hline \multicolumn{2}{|l|}{ Characteristic } & \multicolumn{2}{|l|}{ HIV test result } & \multirow[b]{2}{*}{$P$ value } \\
\hline & & Known $n(\%)$ & Unknown $n(\%)$ & \\
\hline \multirow[t]{3}{*}{ Age group in years } & $0-4$ & $172(48)$ & $457(57)$ & \multirow[t]{3}{*}{0.023} \\
\hline & $5-9$ & $84(23)$ & $162(20)$ & \\
\hline & $10-14$ & $103(29)$ & $189(23)$ & \\
\hline \multirow[t]{3}{*}{ District } & Kampala & $210(59)$ & $475(59))$ & \multirow[t]{3}{*}{0.049} \\
\hline & Wakiso & $86(24)$ & $152(19)$ & \\
\hline & Others & $63(18)$ & $181(22)$ & \\
\hline \multirow{5}{*}{$\begin{array}{l}\text { Division of } \\
\text { Kampala district }\end{array}$} & Central & $10(5)$ & $28(6)$ & \multirow[t]{5}{*}{0.044} \\
\hline & Kawempe & $43(20)$ & $129(27)$ & \\
\hline & Rubaga & $74(35)$ & $142(30)$ & \\
\hline & Makindye & $36(17)$ & $103(22)$ & \\
\hline & Nakawa & $47(22)$ & $73(15)$ & \\
\hline \multirow[t]{2}{*}{ Sex } & Female & $190(53)$ & $358(44)$ & \multirow[t]{2}{*}{0.006} \\
\hline & Male & $169(47)$ & $450(56)$ & \\
\hline \multirow[t]{2}{*}{ TB type } & PTB & 307 (86) & $733(91)$ & \multirow[t]{2}{*}{0.011} \\
\hline & EPTB & $51(14)$ & $75(9)$ & \\
\hline \multirow[t]{2}{*}{ Sputum collected } & Yes & $207(58)$ & $249(31)$ & \multirow[t]{2}{*}{$<0.001$} \\
\hline & No & $151(42)$ & $560(69)$ & \\
\hline
\end{tabular}


Table 3 General characteristics of HIV positive and negative children with TB notified in Kampala district, Uganda, 2009-2010 $(N=359)$

\begin{tabular}{|c|c|c|c|c|}
\hline \multicolumn{2}{|l|}{ Characteristic } & \multicolumn{2}{|l|}{ HIV test result } & \multirow[b]{2}{*}{$P$ value } \\
\hline & & Positive $n(\%)$ & Negative $n(\%)$ & \\
\hline \multirow[t]{3}{*}{ Age group in years } & $0-4$ & $81(48)$ & $91(48)$ & $<0.002$ \\
\hline & $5-9$ & $51(30)$ & $33(17)$ & \\
\hline & $10-14$ & $36(21)$ & $67(35)$ & \\
\hline \multirow[t]{3}{*}{ District } & Kampala & $98(58.33$ & $112(58.64$ & 0.989 \\
\hline & Wakiso & $40(23.81$ & $46(24.08$ & \\
\hline & Others & $30(17.86$ & $33(17.28$ & \\
\hline \multirow[t]{5}{*}{ Division } & Kawempe & $15(15.31$ & $28(25.00$ & 0.158 \\
\hline & Makindye & $19(19.39$ & $17(15.18$ & \\
\hline & Central & $4(4.08$ & $6(5.36$ & \\
\hline & Nakawa & & & \\
\hline & Rubaga & $32(32.65$ & $42(37.50$ & \\
\hline \multirow[t]{2}{*}{ Sex } & Female & $88(52.38$ & $102(53.40$ & 0.846 \\
\hline & Male & $80(47.62$ & $89(46.60$ & \\
\hline \multirow[t]{2}{*}{ TB type } & PTB & $144(85.7$ & $163(85.8)$ & 0.983 \\
\hline & EPTB & $24(14.29)$ & $27(14.21)$ & \\
\hline \multirow[t]{2}{*}{ Sputum collected } & Yes & $103(61.3)$ & $104(54.7$ & 0.208 \\
\hline & No & 65 (38.69) & $86(45.26)$ & \\
\hline
\end{tabular}

negative PTB cases as well as EPTB cases decreased between 2009 and 2010 (see Fig. 1). Distribution of the smear positive cases by age group was; $73 \%(116 / 160)$ among $10-14,15 \%$ (24/160) among 5-9 and $13 \%$ (20/160) among 0-4 years. Distribution of the EPTB cases by age group was: $36 \%(45 / 126)$ among $10-14,37 \%(46 / 126)$ among $0-4$ and $28 \%(35 / 126)$ among 5-9 years old.

\section{Main study results}

The proportion of TB cases in the 0-4 years age group was 52 in 2009 and $56 \%$ in 2010. In the 10-14 years age group the percent was 27 in 2009 and $24 \%$ in 2010 while in the 5-9 years age group it was 21 in 2009 and $20 \%$ in 2010 .

The overall child TB incidence in Kampala was 56 (95\% CI 50-62) per 100,000 in 2009 and 44 (95\% CI $40-49)$ per 100,000 in 2010 . The child TB incidences by age group and division also decreased over the study period as shown in Fig. 2.

Most of the TB cases, $60 \%(410 / 685)$, in Kampala lived in slum areas. The Fig. 3 shows distribution of TB cases by area and division.

\section{Discussion \\ Main findings}

Our findings showed a general decrease in TB incidence with most cases of PTB having no smear done and majority of EPTB cases occurring among adolescents. We found a high rate of smear positive cases of up to $15 \%$. Our study highlights low HIV test uptake, high absence of HIV test results and large percentage TB cases residing in slum areas in the Kampala district.

\section{Relation to literature}

Our findings showed that many cases registered in Kampala district live outside the Kampala administrative borders. The incident cases registered in Kampala district may therefore not represent the true picture of TB burden within the various communities in Kampala district.

We noted a decrease in TB incidence over the review period similar to that in the World TB report 2011 [12]. The report shows a declining trend in TB incidence in adults. This trend should reflect in children as we know that TB cases in children especially those below 5 years represents recent transmission in the community $[13,14]$. Previous work showed that up to $30 \%$ of the children with TB will have an identifiable household source case

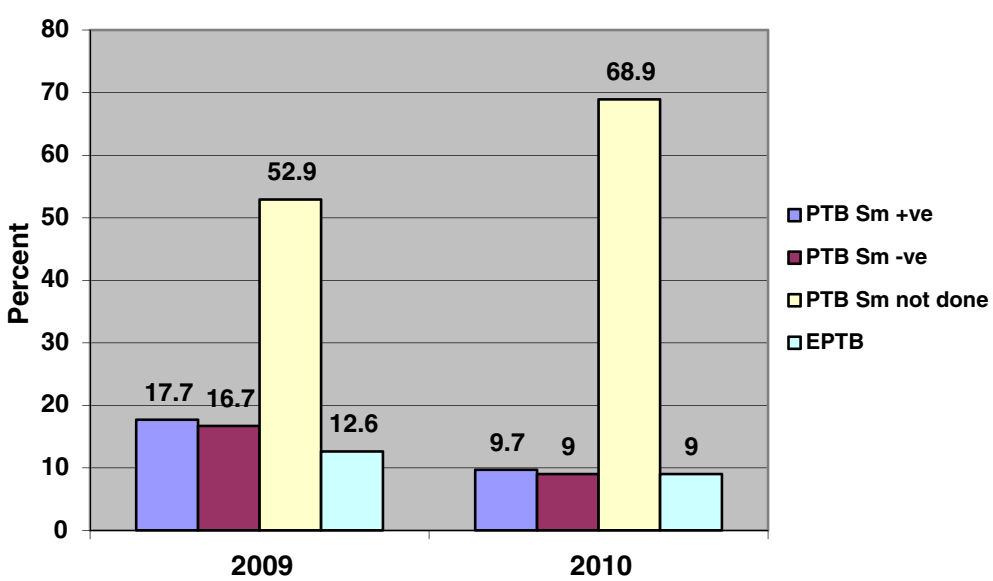

Fig. 1 Distribution of TB types in children in Kampala district, Uganda 2009, $2010(N=1167)$ 


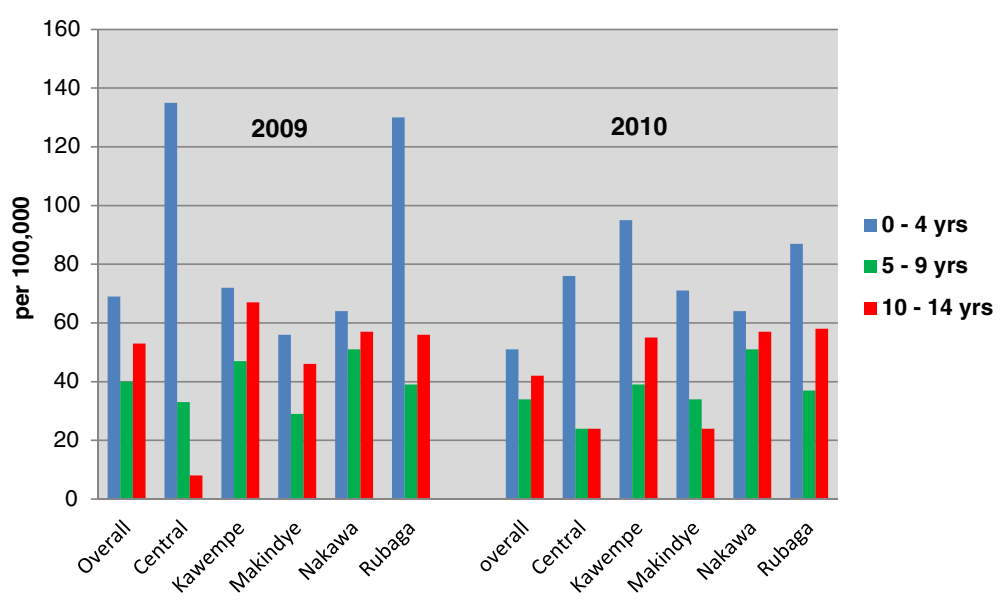

Fig. 2 Childhood TB incidence by age group and division in Kampala district, Uganda 2009, 2010

[15]. Similar to previous reports, our data shows a bimodal distribution with more cases in under five and 10-14 years age groups compared with the 5-9 year olds $[16,17]$.

Our study found the total number of TB cases had not substantially reduced (the reported TB cases decreased by $8 \%$ ) over the review period. The reported decreased incidence may be due to high population growth rate without the proportionate increase in the number of new TB cases. We however report an increased TB incidence in the under fives that we suppose is attributable to improved diagnosis and reporting rather than increasing burden of $\mathrm{TB}$ in children. Our report shows that $7.5 \%$ of the TB cases registered in Kampala district were among children. This is much higher than the national average of $1.5 \%$ reported in the world TB report 2013 but less than the estimated expected burden of 15-20\% in the high burden countries [2]. The World TB report 2014 still documented that childhood TB represents
$1.5 \%$ of the total cases with no decline in the total number of new cases [18]. We suppose that this discrepancy is due not reporting PTB cases in children with smear negative disease or smear not done. The increased child TB case detection in the under fives is an encouraging finding during this review period. This finding may be a spill over from Tuberculosis control assistance program (TB CAP) activities that included health worker training and provision of tools for TB care [19]. There is evidence that training health workers and provision of the relevant job aids in the diagnosis of children TB increases childhood TB detection rates [20]. Finding more children with no sputum examinations done on the background of several efforts to increase TB detection in children needs innovative ways to cause routine sputum collection from children. The high number of smear not done cases in children is likely due to limited health worker confidence and skills to collect sputum from children. This means most children are diagnosed on

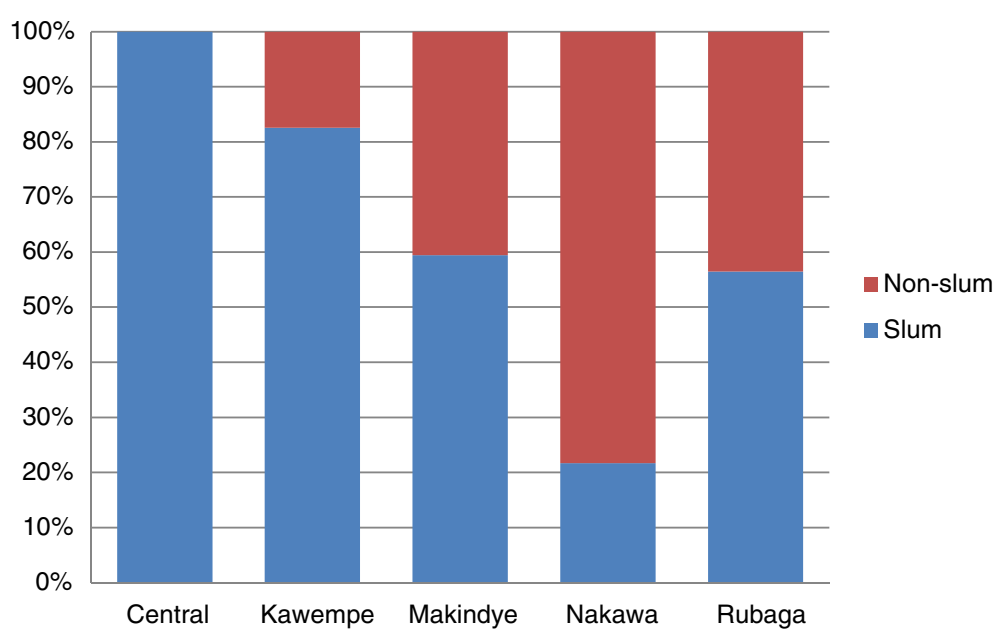

Fig. 3 Distribution of residence of TB cases residing in Kampala District, Uganda 2009-2010 (N=685) 
clinical basis with no sputum collection. The reality of multi-drug resistant (MDR) TB makes it even more pressing to build capacity for sputum collection from children.

The lowest TB incidence was in the 5-9 year age group, a safer age group as reported in literature [16]. Most of the childhood TB cases (56\%) were in children below 5 years old. This age group has the highest risk of developing $\mathrm{TB}$ disease because of low immunity and other reasons such as malnutrition and HIV $[8,21]$. This age group is more likely to get exposure for longer periods to infectious adults within their households [22].

We found most $\mathrm{TB}$ cases were pulmonary, a finding reported by other studies [23, 24]. A TB report from Zambia showed that about $72 \%$ of childhood TB cases were pulmonary [25]. Even for the children less than five years old we report more PTB cases than EPTB. Literature reports children are more prone to EPTB most especially if HIV positive [26]. However, we report more cases of PTB than EPTB even when the HIV prevalence was high among the tested patients. We found equal proportions of children with HIV among the PTB and EPTB cases. We expect a higher proportion with EPTB in a population of children with high HIV co-infection and low ART uptake at $24 \%$ on the premise that children are prone to disseminated disease if HIV infected. This finding also reported in other settings [23-25] may be related to training of health workers that mainly focuses on PTB. It is possible the EPTB cases are largely missed. Finding about forty per cent EPTB cases among adolescents is unexpected since at this age there is more TB containment outside the lungs. The available data neither included the sites of EPTB nor provided an explanation for this observation. A study of incident TB cases among adolescents in South Africa found only $3 \%$ had EPTB [27]. The total child TB cases reported in the 2010 and 2011 Global TB reports is 1291 for Uganda while we report 1167 child TB cases for Kampala district alone during the same time period. Our report underpins the reality of child TB under-reporting because of the emphasis on reporting smear positive cases only.

We report an overall smear positivity rate of $15 \%$ among those tested and most of these (72 \%) were adolescents $10-14$ years. We report a high positive smear rate ranging from $13 \%$ in $0-4$ years to $15 \%$ among children $10-14$ years. The smear positivity rate among adolescents is similar to the adult smear positivity rate of 20 \% reported in Uganda in 2007 [28]. This is not surprising since adolescents get adult type pulmonary disease. We report a smear positivity rate of $13 \%$ among those below 5 years. This suggests that routine use of $\mathrm{Xpert}^{\circ} \mathrm{MTB} / \mathrm{RIF}$ as recommended in this age group would yield many more bacteriologically confirmed cases in the under fives. The Xpert ${ }^{\circ}$ MTB/RIF is a hands-free sample real-time PCR analysis system, developed under Cepheid (a molecular diagnostics company), that simultaneously detects mycobacterium tuberculosis (MTB) and resistance to rifampicin (RIF). In our previous study in a research setting, Xpert ${ }^{\circ} \mathrm{MTB} /$ RIF identified twice as many cases as microscopy [29].

The low HIV testing and results availability reported in this paper suggests gaps in integration of TB and HIV services. A similar finding was reported in nonintegrated TB and HIV services in South Africa where only $26 \%$ of the TB patients knew their HIV status. In the same report, the number tested for HIV was low at diagnosis compared to at 2 or 6 months while on $\mathrm{TB}$ treatment [30].

There were many TB cases residing outside Kampala district but registered and treatment in Kampala. This finding may reflect limited confidence and capacity of health workers outside Kampala district to diagnose TB in children. The likely implication is potential increase in TB transmission by caregivers (who are the likely source of TB) during their travel by public transport to access services in Kampala district. This exposure may vary from as short as $10 \mathrm{~min}$ to as long as one hour depending on the traffic flow and distance to the health units in Kampala. We found TB cases clustered in particular areas especially slum areas. Most of TB cases originate from slum areas. This observation may represent ongoing transmission in these areas. A study in high TB incidence urban setting in South Africa found $72 \%$ of the cases were clustered within slum communities [31]. We found similar TB case notifications in the same slum areas over the two years of our report. This suggests the transmission cycle in those particular slum areas is uninterrupted.

\section{Strengths and limitations}

This is the first report to document the burden of TB in Kampala from the routine programmatic data. We collected all the data reported in Kampala district during the review period for at least two years. At the minimum this would provide insight on TB epidemiology in children in Kampala district. We conducted this work before availability of Xpert ${ }^{\circ}$ MTB/RIF in Kampala provides important comparative data in assessing the impact of Xpert $^{\circ}$ MTB/RIF wide use on TB detection in children.

We acknowledge some limitations to this work. We had two data points (2009 and 2010) which are not enough to show a trend in TB epidemiology constituting a selection bias. There is no comparative published childhood TB data for Kampala district to affirm our the observation as part of a national downward trend of $\mathrm{TB}$ incidence in Uganda [18]. We could not confirm the accuracy of the TB diagnoses. We report the bacteriologically confirmed cases based on only sputum smears 
which is an under estimate. Work done in South Africa found $22 \%$ of the children with TB were smear negative but culture positive [27]. We used programmatic data that did not capture important aspects of paediatric TB epidemiology such as TB contact history, those on isoniazid preventive therapy and BCG vaccination status. The population projections we used depend on birth rates but for urban settings in Uganda population growth is mainly because in-migrations. Also population projects beyond 10 years become increasingly inaccurate. This is a reasonable explanation for the wide confidence intervals around our incidence estimates. We believe this is the best estimate within our limitations.

\section{Implication for practise, policy and research}

This paper highlights the reality of under-reporting of childhood TB where documenting all childhood TB cases would improve the estimates. The sputum collection for $\mathrm{TB}$ detection in children was low and there is need to understand the underlying reasons. Assuming limited skills and knowledge of health workers as the explanation for low sputum collection in children may only be part of a larger problem. The finding that many children reside outside Kampala district but are diagnosed and treated in Kampala district requires further study. Contacts of smear positive cases were not captured in the unit TB registers representing missed opportunities for control of TB. The reality of large number of $\mathrm{TB}$ cases arising from the same slum areas means that targeted TB control interventions would break this cycle. In this study we noted the TB cases remained clustered in the same slum areas over the review period. The finding that $100 \%$ of TB cases in the central division of Kampala resided in slum areas requires specific TB control interventions at household level. Using private health units in the slum areas to detect and treat TB has proved an effective intervention that is worthy strengthening. The Slum Partnerships to Actively Respond to Tuberculosis in Kampala (SPARK-TB) project showed impact of this approach by being able to identify an extra 1267 smear positive cases [32].

\section{Conclusions}

There was a reduction in child TB incidence in Kampala district over the review period. The incidence was 56 per 100,000 in 2009 and 44 per 100,000 in 2010. The number of child TB cases was much higher at $7.5 \%$ of all cases during the review period compared to the national average of $2.5 \%$ in the world TB reports 2010, 2011. There was a high HIV co-infection rate and low antiretroviral uptake over the review period. Pulmonary TB remains the commonest form of $\mathrm{TB}$ in children with children below five years bearing the biggest burden. For the review period, the TB cases clustered in particular Kampala district slum areas.

\section{Competing interest}

The authors declare that they have no competing interests.

\section{Authors' contributions}

EW conceived the research idea, developed the proposal, interpreted the data and wrote the manuscript draft. DL helped to develop the research proposal, collected the data, analysed, interpreted the data and contributed to the manuscript writing. IL helped in developing the research proposal, data interpretation and contributed the manuscript. FM contributed to interpreting and writing of the manuscript. MS contributed to interpreting and writing of the manuscript. PM contributed to interpreting and writing of the manuscript. All the authors read and approved the manuscript.

\section{Authors' information}

Not applicable.

\section{Acknowledgements}

We thank the District TB \& Leprosy supervisors that ensured accurate data records. We thank Ms Winnie Nayebare who collected the data into the study database. This work received no external funding.

\section{Author details}

'Directorate of Paediatrics \& Child health, Mulago National Referral Hospital, P. O. Box 7051, Kampala, Uganda. ${ }^{2}$ MU-JHU Research Collaboration, P. O. Box 23491, Kampala, Uganda. ${ }^{3}$ TRACK TB Project, Management Sciences for Health, P. O. Box 71419, Kampala, Uganda. ${ }^{4}$ Uganda National TB \& Leprosy Programme, P. O. Box 7272, Kampala, Uganda. ${ }^{5}$ Department of Paediatrics \& Child Health, Makerere University College of Health Sciences, P. O. Box 7062, Kampala, Uganda.

\section{Received: 15 June 2015 Accepted: 22 September 2015}

Published online: 25 September 2015

\section{References}

1. WHO. Global tuberculosis report 2012. Geneva: World Health Organisation; 2012. Report No:: 9789241564502.

2. Dodd PJ, Gardiner E, Coghlan R, Seddon JA. Burden of childhood tuberculosis in 22 high-burden countries: a mathematical modelling study. Lancet Glob Health. 2014;2(8):e453-9.

3. UNAIDS. report on the global AIDS epidemic 2013. Geneva: Joint United Nations Programme on HIV/AIDS (UNAIDS); 2013.

4. WHO. Global tuberculosis report. Geneva: WHO; 2013.

5. Ministry of Finance, Planning and Economic Development. Millennium Development Goals Report for Uganda 2013. 2013.

6. Rekha B, Swaminathan S. Childhood tuberculosis - global epidemiology and the impact of HIV. Paediatr Respir Rev. 2007:8(2):99-106.

7. Marais BJ, Gie RP, Schaaf HS, Hesseling AC, Obihara CC, Nelson $\sqcup$, et al. The clinical epidemiology of childhood pulmonary tuberculosis: a critical review of literature from the pre-chemotherapy era. Int J Tuberc Lung Dis. 2004;8(3):278-85.

8. van Rie A, Beyers N, Gie RP, Kunneke M, Zietsman L, Donald PR. Childhood tuberculosis in an urban population in South Africa: burden and risk factor. Arch Dis Child. 1999;80(5):433-7.

9. Marais BJ, Obihara CC, Warren RM, Schaaf HS, Gie RP, Donald PR. The burden of childhood tuberculosis: a public health perspective. Int J Tuberc Lung Dis. 2005;9(12):1305-13.

10. UGANDA BUREAU OF STATISTICS. Uganda Population and Housing Census 2002 Reports. Kampala: UGANDA BUREAU OF STATISTICS; 2002. http:// www.ubos.org/unda/index.php/catalog/46/download/146.

11. World Health Organisation. Guidance for national tuberculosis programmes in the management of tuberculosis in children. Geneva: World Health Organisation; 2006. p. 8.

12. WHO. Global tuberculosis control. Geneva: WHO; 2011.

13. Marais BJ, Gie RP, Schaaf HS, Hesseling AC, Enarson DA, Beyers N. The spectrum of disease in children treated for tuberculosis in a highly endemic area. Int J Tuberc Lung Dis. 2006;10(7):732-8.

14. Middelkoop K, Bekker LG, Morrow C, Zwane E, Wood R. Childhood tuberculosis infection and disease: a spatial and temporal transmission analysis in a South African township. S Afr Med J. 2009;99(10):738-43. 
15. De D, Kinikar A, Adhav PS, Kamble S, Sahoo P, Koli H, et al. Source case investigation for children with TB disease in pune. India Tuberc Res Treat. 2014;2014:182836.

16. Comstock GW, Livesay VT, Woolpert SF. The prognosis of a positive tuberculin reaction in childhood and adolescence. Am J Epidemiol. 1974;99(2):131-8.

17. Sandgren A, Hollo V, Quinten C, Manissero D. Childhood tuberculosis in the European Union/European Economic Area, 2000 to 2009. Euro Surveill. 2011;16(12).

18. WHO. Global tuberculosis report. Geneva: WHO; 2014.

19. TB CAP Final Report 2005-2010 [database on the Internet]. TB CARE I Program Management Unit. Available from: file:///C:/downloads/TB_CAP_ Final_Report_2005-2010.pdf.

20. Talukder K, Salim MA, Jerin I, Sharmin F, Talukder MQ, Marais BJ, et al. Intervention to increase detection of childhood tuberculosis in Bangladesh. Int J Tuberc Lung Dis. 2012;16(1):70-5.

21. Singh M, Mynak ML, Kumar L, Mathew JL, Jindal SK. Prevalence and risk factors for transmission of infection among children in household contact with adults having pulmonary tuberculosis. Arch Dis Child. 2005;90(6):624-8.

22. Beyers N, Gie RP, Schaaf HS, Van Zyl S, Talent JM, Nel ED, et al. A prospective evaluation of children under the age of 5 years living in the same household as adults with recently diagnosed pulmonary tuberculosis. Int J Tuberc Lung Dis. 1997;1(1):38-43.

23. Sreeramareddy CT, Ramakrishnareddy N, Shah RK, Baniya R, Swain PK. Clinico-epidemiological profile and diagnostic procedures of pediatric tuberculosis in a tertiary care hospital of western Nepal-a case-series analysis. BMC Pediatr. 2010;10:57.

24. Hailu D, Abegaz WE, Belay M. Childhood tuberculosis and its treatment outcomes in Addis Ababa: a 5-years retrospective study. BMC Pediatr. 2014;14:61.

25. Kapata N, Chanda-Kapata P, O'Grady J, Bates M, Mwaba P, Janssen S, et al. Trends in childhood tuberculosis in Zambia: a situation analysis. J Trop Pediatr. 2013;59(2):134-9.

26. Verhagen LM, Warris A, van Soolingen D, de Groot R, Hermans PW. Human immunodeficiency virus and tuberculosis coinfection in children: challenges in diagnosis and treatment. Pediatr Infect Dis J. 2010;29(10):e63-70. doi:10.1097/INF.0b013e3181ee23ae.

27. Mahomed H, Ehrlich R, Hawkridge T, Hatherill M, Geiter L, Kafaar F, et al. TB incidence in an adolescent cohort in South Africa. PLoS One. 2013;8(3), e59652.

28. Katamba A, Laticevschi D, Rieder HL. Efficiency of a third serial sputum smear examination in the diagnosis of tuberculosis in Moldova and Uganda. Int J Tuberc Lung Dis. 2007;11(6):659-64.

29. Sekadde MP, Wobudeya E, Joloba ML, Ssengooba W, Kisembo H, BakeeraKitaka S, et al. Evaluation of the Xpert MTB/RIF test for the diagnosis of childhood pulmonary tuberculosis in Uganda: a cross-sectional diagnostic study. BMC Infect Dis. 2013;13:133.

30. Coetzee D, Hilderbrand K, Goemaere E, Matthys F, Boelaert M. Integrating tuberculosis and HIV care in the primary care setting in South Africa. Trop Med Int Health. 2004;9(6):A11-5.

31. Verver S, Warren RM, Munch Z, Vynnycky E, van Helden PD, Richardson M, et al. Transmission of tuberculosis in a high incidence urban community in South Africa. Int J Epidemiol. 2004;33(2):351-7.

32. Slum Partnerships to Actively Respond to Tuberculosis in Kampala District (SPARK-TB) [database on the Internet]2014. Available from: http:// www.theunion.org/what-we-do/publications/general/english/SPARKTB_end-of-project-report_Final.pdf.

\section{Submit your next manuscript to BioMed Central and take full advantage of:}

- Convenient online submission

- Thorough peer review

- No space constraints or color figure charges

- Immediate publication on acceptance

- Inclusion in PubMed, CAS, Scopus and Google Scholar

- Research which is freely available for redistribution 